\title{
GAMBARAN GAYA HIDUP PENDERITA HIPERTENSI \\ DI PUSKESMAS ATAMBUA SELATAN
}

\author{
Florida Baso*) \\ Pius A. L. Berek*) \\ Elfrida Dana F. Riwoerohi*)
}

*) Program Studi Keperawatan Universitas Timor Kampus Atambua, Jl. Wehor Kabuna Haliwen Atambua Nusa Tenggara Timur. Post: 85711. Phone: 081280426042. Email: francis_domin2012@yahoo.com

\begin{abstract}
ABSTRAK
Hipertensi adalah istilah medis untuk penyakit tekanan darah tinggi dan merupakan salah satu masalah kesehatan masyarakat yang banyak di derita di seluruh Indonesia. Gaya hidup seperti faktor makanan, aktifitas fisik, stress dan merokok juga menjadi faktor yang mendukung terjadinya hipertensi. Penelitian ini bertujuan untuk menggambarkan gaya hidup penderita hipertensi. Jenis penelitian ini adalah kuantitatif dengan menggunakan desain deskriptif dengan pendekatan cross sectional. Penelitian ini digunakan untuk mengetahui gambaran gaya hidup penderita hipertensi di Puskesmas Atambua Selatan. Sampel pada penelitian ini berjumlah 55 penderita hipertensi yang ada di Puskesmas Atambua Selatan Kabupaten Belu. Pengumpulan data menggunakan kuesioner yang menilai kebiasaan merokok, kebiasaan makan, aktivita sfisik dan stress. Hasil penelitian menunjukkan bahwa sebanyak 38 orang $(69,1 \%)$ tidak memiliki kebiasaan merokok, responden yang memiliki kebiasaan makan makanan asin yaitu sebanyak 34 orang $(61,8 \%)$, makan berlemak sebanyak 36 orang $(65,5 \%)$, makanan instan sebanyak 31 orang $(56,4 \%)$. Responden sesuai tingkat aktivitas fisik menunjukkan bahwa sebagian responden rutin melakukan olahraga sebanyak 37 orang $(67,3 \%)$, keadaan stress dapat diketahui bahwa dari 55 responden sebanyak 22 orang (40\%) tidak mengalami stress.
\end{abstract}

Kata Kunci: Gaya Hidup, Penderita Hipertensi dan Masyarakat.

\section{DESCRIPTION OF LIFESTYLE HYPERTENSION PATIENTS AT HEALTH CENTRE OF SOUTH ATAMBUA}

\author{
Florida Baso*) \\ Pius A. L. Berek*) \\ Elfrida Dana F. Riwoerohi*) \\ *) Nursing Program at University of Timor Atambua Campus, Jl. Wehor Kabuna Haliwen Atambua East Nusa Tenggara. Post: \\ 85711. Phone: 081280426042. Email: francis_domin2012@yahoo.com
}

Hypertension is a medical term for high blood pressure disease and it is one of the many public health problems suffered throughout Indonesia. Lifestyle such as food factors, physical activity, stress and smoking are also factors that support the occurrence of hypertension. This study aims to describe the lifestyle of people with hypertension. This type of research is quantitative using descriptive design with cross sectional approach. This study was used to describe the lifestyle of hypertensive patients at the Health Center of South Atambua. The sample in this study amounted to 55 hypertensive patients at the Health Center of South Atambua in Belu District. Data collection uses questionnaires that assess smoking habits, eating habits, physical and stressful activities. The results showed that as many as 38 people $(69.1 \%)$ did not have smoking habits, respondents who had salty food eating habits were as many as 34 people (61.8\%), fatty meals as many as 36 people $(65.5 \%)$, instant food 31 people (56.4\%). Respondents according to the level of physical activity showed that some respondents routinely exercised as many as 37 people $(67.3 \%)$, stressful conditions can be seen that from 55 respondents as many as 22 people (40\%) did not experience stress.

Keywords: Lifestyle, Hypertension Patients and Society 


\section{PENDAHULUAN}

Hipertensi adalah istilah medis untuk penyakit tekanan darah tinggi dan merupakan salah satu masalah kesehatan masyarakat yang banyak di derita di seluruh Indonesia. Hipertensi merupakan keadaan dimana tekanan darah dalam pembuluh darah meningkat secara kronis. Hal tersebut dapat terjadi karena jantung bekerja lebih keras memompa darah untuk memenuhi kebutuhan oksigen dan nutrisi tubuh (Herawati, 2016). Hipertensi juga dapat diartikan sebagai salah satu penyakit kardiovaskular dimana penderita memiliki tekanan darah diatas normal yang ditandai dengan nilai sistol lebih dari 140 $\mathrm{mmHg}$ dan diastol lebih dari $90 \mathrm{mmHg}$ (Handayani, dkk 2015).

World Health Organization (WHO) dan The International Society of Hipertension menyatakan saat ini terdapat 600 juta penderita hipertensi di seluruh dunia.WHO juga mengatakan tahun 2002 di Jenewa prevelensi penyakit hipertensi $15-35 \%$ dari populasi penduduk dewasa di dunia. Pada tahun 2005 di Amerika penderita hipertensi sekitar 21,7\%. Pada tahun 2008 penderita hipertensi mengalami peningkatan sekitar satu miliar orang di seluruh dunia dan diperkirakan tahun 2025 akan mengalami peningkatan sekitar 1,6 miliar. Data WHO bulan September 2011 juga menyatakan hipertensi menyebabkan 8 juta kematian per tahun di seluruh dunia (Kartikasari, 2012). Hasil dari Riskesdas 2013 prevelensi hipertensi di Indonesia yang di dapat melalui pengukuran pada umur $\geq 18$ tahun sebesar $2,8 \%$, tertinggi di Bangka Belitung (30,09\%), diikuti Kalimantan Selatan $(29,6 \%)$, dan Jawa Barat $(29,4 \%)$. Untuk prevelensi provinsi Sulawesi Utara berada di posisi ke 7 dari 33 provinsi yang ada di Indonesia yaitu sebesar 27,1\% (Sinubu, dkk, 2015). Hasil Riskesdas tahun 2013 prevalensi hipertensi hasil wawancara di seluruh Provinsi Nusa Tenggara Timur adalah 7,2 persen dan berada di bawah angka nasional yang mencapai 9,4 persen. Tiga kabupaten/ kota dengan prevalensi tertinggi hipertensi hasil pengukuran adalah Kupang (5,5 \%), Timor Tengah Selatan $(4,4 \%)$, Timor Tengah Utara (5,5 \%), dan Belu (2,5 \%) (Profil Manajeman Kesehatan, 2014). Data Dinas Kesehatan Kabupaten Belu pada tahun 2018 periode Januari sampai Desember angka kejadian penderita hipertensi di Puskesmas Atambua Selatan Tergolong cukup tinggi dengan jumlah 763 yang terdiri dari $310(41 \%)$ laki-laki, $453(59,37 \%)$ perempuan.

Faktor perubahan gaya hidup diduga telah menyebabkan peningkatan besar kasus - kasus penyakit tidak menular di Indonesia, termasuk dalam hal ini adalah hipertensi. Gaya hidup seperti faktor makanan, aktifitas fisik, stress dan merokok juga menjadi factor yang mendukung terjadinya hipertensi. Berdasarkan laporan hasil Riskesdas menggambarkan hampir disemua provinsi di Indonesia, konsumsi sayuran dan buah - buahan terggolong rendah.Serta secara nasional konsumsi makanan asin, kebiasaan merokok, serta aktifitas fisik yang kurang, istirahat dan tingkat stressor masih cukup tinggi prevalensinya (Nisa, 2018).Hipertensi yang disertai penyakit penyerta adalah salah satu penyebab kematian nomor satu di dunia.Komplikasi pembuluh darah yang disebabkan hipertensi dapat menyebabkan penyakit jantung koroner, infark (kerusakan jaringan), jantung, stroke, dan gagal ginjal (Calhoun et al, 2008 dalam Riza, 2017).Diketahui juga hubungan antara hipertensi dengan diabetes melitus sangat kuat karena beberapa kriteria yang sering ada pada pasien hipertensi yaitu peningkatan tekanan darah, obesitas dan peningkatan glukosa darah (Sasen dan Carter, 2008).

Pengobatan hipertensi terdiri dari terapi farmakologis dan non farmakologis. Terapi farmakologis dilakukan dengan pemberian obat anti hipertensi sedangkan terapi non farmakologis diantaranya adalah gaya hidup sehat seperti berhenti merokok, menurunkan berat badan berlebih, latihan fisik, menurunkan asupan garam, meningkatkan asupan sayur dan buah dan mengurangi asupan lemak. Salah satu metode pengobatan pengurangan nyeri kepala dengan terapi non farmakologi yaitu dengan metode relaksasi otot progresif.Teknik relaksasi otot progresif adalah memusatkan perhatian pada suatu aktivitas otot, dengan mengidentifikasikan otot yang tegang kemudian menurunkan ketegangan dengan melakukan teknik relaksasi untuk mendapatkan perasaan relaks (Purwanto, 2013 dalam Saputri 2016). Selanjutnya Berek, et al (2015) dalam penelitiannya menemukan bahwa mengatur pernapasan yang dalam dan 
lambat kurang dari 10 kali per menit selama 15 menit dapat dapat menurunkan tekanan darah sistolik sebesar $28,59 \mathrm{mmHg}$ dan tekanan darah diastolic sebesar 16, $92 \mathrm{mmHg}$. Mengatur nafas dalam dan lambat serta diet rendah garam $12 \mathrm{gr} / \mathrm{hari}$ juga dapat menurunkan tekanan darah secara efektif. Proses pengaturan nafas dalam dan lambat serta pengaturan diet dapat dijadikan sebagai dasar terapi non farmakologi dan sebagai pola hidup yang efektif untuk menurunkan tekanan darah pada penderita hipertensi (Berek, 2018).

\section{METODOLOGI}

Penelitian ini merupakan penelitian deskriptif yang pendekatan cross sectioan untuk mengetahui gambaran pola hidup pasien hipertensi di Puskesmas Atambua Selatan. Dengan menggunakan metode accidental sampling, diperoleh responden sebanyak 55 orang, dengan kriteria inklusi bersedia menjadi responden; dan penderita hipertensi di Puskesmas Atambua Selatan. Pengumpulan data dengan menggunakan data sekunder yaitu data yang diperoleh dari rekapitulasi penderita hipertensi di Puskesmas Atambua Selatan, data primer dari kuesioner yang dibagikan pada responden dengan menggunakan teknik accidental sampling. Accidental sampling adalah sampel diambil pada kasus atau responden yang kebetulan ada atau tersedia.

Pengolahan data dilakukan secara manual dengan mengisi kuesioner yang sudah dsediakan, selanjutnya menggunakan bantuan computer.

\section{HASIL PENELITIAN}

a. Karakteristik responden.

Tabel 1

Distribusi Responden Berdasarkan Umur (N: 55 orang)

\begin{tabular}{ccccc}
\hline Varibel & $\begin{array}{c}\text { Mean } \\
\text { Median }\end{array}$ & $\begin{array}{c}\text { Standar } \\
\text { Deviasi }\end{array}$ & $\begin{array}{c}\text { Minimum } \\
\text { Maxmun }\end{array}$ & $\begin{array}{c}95 \% \\
\text { CI }\end{array}$ \\
\hline Umur & 54,18 & 12,554 & 27 & 50,79 \\
& 54,00 & & 80 & 57,58 \\
\hline
\end{tabular}

Sumber: Data Primer, 2019

Hasil analisis didapatkan rata-rata umur responden adalah 54,18 tahun (95\% CI : $50,79 ; 57,58)$, dengan standar deviasi 12,554 tahun. Umur termuda27 tahun dan umur tertua adalah 80 tahun. Dari hasil estimasi interval dapat disimpulkan bahwa 95\% diyakini bahwa rata-rata umur responden adalah diantara 50,79 sampai dengan 57,58 tahun

\section{Tabel 2}

Distribusi Frekuensi Responden Berdasarkan Jenis Kelamin

\begin{tabular}{ccc}
\hline Jenis kelamin & Frekuensi & Persentase \% \\
\hline Laki- laki & 28 & 50,9 \\
Perempuan & 27 & 49,1 \\
\hline Jumlah & $\mathbf{5 5}$ & $\mathbf{1 0 0}$
\end{tabular}

Sumber: Data Primer, 2019

Berdasarkan tabel di atas hasil penelitian distribusi responden berdasarkan jenis kelamin didapat responden terbanyak pada jenis kelamin laki-laki yaitu 28 orang $(50,9 \%)$ sedangkan perempuan sebanyak 27 orang $(49,1 \%)$.

\section{Tabel 3}

Distribusi Frekuensi Responden

Berdasarkan Tingkat Pendidikan

\begin{tabular}{ccc}
\hline Tingkat Pendidikan & Frekuensi & Persentase \% \\
\hline SD & 10 & 18,2 \\
SLTP & 21 & 38,2 \\
SLTA & 17 & 30,9 \\
Perguruan Tinggi & 7 & 12,7 \\
\hline Jumlah & $\mathbf{5 5}$ & $\mathbf{1 0 0}$
\end{tabular}

Sumber: Data Primer, 2019

Distribusi tingkat pendidikan responden yang paling banyak yaitu pada kelompok SLTP sebanyak 21 orang $(38,2 \%)$ diikuti oleh kelompok SLTA sebanyak 17 orang $(30,9 \%)$ kemudian kelompok SD sebanyak 10 orang $(18,2 \%)$ dan tingkat pendidikan yang terendah yaitu Pendidikan tinggi sebanyak 7 orang $(12,7 \%)$

\section{Tabel 4}

Distribusi Frekuensi Responden Berdasarkan Tingkat Pekerjaan

\begin{tabular}{lcc}
\hline \multicolumn{1}{c}{ Pekerjaan } & Frekuensi & Persentase \% \\
\hline Pensiun & 8 & 14,5 \\
Swasta & 13 & 23,6 \\
Tidak Bekerja & 27 & 49,1 \\
Wiraswasta & 7 & 12,7 \\
\hline Jumlah & $\mathbf{5 5}$ & $\mathbf{1 0 0}$ \\
\hline
\end{tabular}

Sumber: Data Primer, 2019 
Berdasarkan tabel di atas distribusi frekuensi responden berdasarkan pekerjaan didapat responden terbanyak yaitu tidak bekerja sebanyak 27 orang $(49,1 \%)$ kemudian diikuti oleh responden swasta sebanyak 13 orang $(23,6 \%)$ dan yang pensiun sebanyak 8 orang $(14,5 \%)$ dan responden yang memiliki pekerjaan terendah yaitu wiraswasta sebanyak 7 orang $(12,7 \%)$.

Tabel 5

Distribusi Frekuensi Responden Berdasarkan Penyakit Komplikasi

\begin{tabular}{ccc}
\hline Komplikasi & Frekuensi & Persentase \% \\
\hline Gagal Ginjal & 1 & 1,8 \\
Stroke & 1 & 1,8 \\
Tidak ada & 53 & 96,4 \\
\hline Jumlah & $\mathbf{5 5}$ & $\mathbf{1 0 0}$
\end{tabular}

Sumber: Data Primer, 2019

Berdasarkan tabel di atas distribusi frekuensi responden berdasarkan penyakit komplikasi yaitu sebagian besar responden tidak memiliki penyakit komplikasi yaitu sebanyak 53 orang $(94,4 \%)$ sedangkan yang mengalami komplikasi gagal ginjal yaitu 1 orang $(1,8 \%)$ dan stroke 1 orang $(1,8 \%)$.

Tabel 4.6

Diistribusi Frekuensi Responden Berdasarkan Nadi dan Tekanan Darah

\begin{tabular}{lcccc}
\hline Variabel & $\begin{array}{c}\text { Mean } \\
\text { Median }\end{array}$ & $\begin{array}{c}\text { Standar } \\
\text { Deviasi }\end{array}$ & $\begin{array}{c}\text { Minimum } \\
\text { Maximun }\end{array}$ & $\begin{array}{c}95 \% \\
\text { CI }\end{array}$ \\
\hline Nadi & 84,58 & 7,410 & 66 & 82,58 \\
& 84,00 & & 102 & 86,59 \\
Tekanan & & & & \\
Darah: & 92,78 & 1,227 & 132 & 152,55 \\
Sistolik & 155,00 & & 180 & 159,16 \\
Tekanan & & & 73 & 90,64 \\
Darah: & 92,85 & 7,853 & 117 & 94,89 \\
Diastoli & 90,00 & & & \\
k & & &
\end{tabular}

Hasil analisis didapatkan rata-rata nadi responden dalam penelitian ini adalah 84,58 kali permenit $(95 \% \mathrm{CI}: 82,58 ; 86,59)$, dengan standar deviasi 7, 410. Nadi terendah 66 kali permenit dan nadi tertinggi 102 kali permenit. Dari hasil estimasi interval dapat disimpulkan bahwa 95\% diyakini bahwa rata-rata nadi responden adalah diantara 82,58 sampai dengan 86,59 kali permenit.

Rata-rata tekanan darah sistolik responden dalam penelitian ini adalah 92,78 mmHg $(95 \%$ CI : 152,55 ; 159,16), dengan standardeviasi 1,227. Tekanan darah sistolik terendah $132 \mathrm{mmHg}$ dan tekanan darah sistolik tertinggi $180 \mathrm{mmHg}$. Dari hasil estimasi interval dapat disimpulkan bahwa 95\% diyakini bahwa rata-rata tekanan darah sistolik pada responden adalah diantara 152,55 sampai dengan 159,16 mmHg. Sedangkan tekanan darah diastolik pada responden hipertensi dalam penelitian ini adalah 92,85 mmHg (95\% CI : 90,64; 94,89), dengan standar deviasi 7,853. Tekanan darah diastolik terendah $73 \mathrm{mmHg}$ dan tekanan darah diastolik tertinggi $117 \mathrm{mmHg}$.

Dari hasil estimasi interval dapat disimpulkan bahwa 95\% diyakini bahwa ratarata tekanan darah diastolik pada responden adalah diantara 90,64 sampai dengan 94,89 $\mathrm{mmHg}$.

Tabel 7

Distribusi Frekuensi Responden Berdasarkan Kebiasaan Merokok

\begin{tabular}{cccc}
\hline No & Variabel & Frekuensi & $\begin{array}{c}\text { Presentase } \\
\mathbf{\%}\end{array}$ \\
\hline 1 & Kebiasaan & & \\
& merokok : & & \\
& Ya & 17 & 30,9 \\
& Tidak & 38 & 69,1
\end{tabular}

2 Perokok dirumah :

$\begin{array}{ccc}\text { Ya } & 35 & 63,6 \\ \text { Tidak } & 20 & 36,4\end{array}$

$\begin{array}{lll}\text { Papaan asap } & & \\ \text { rokok } & & \\ \text { dikantor: } & & \\ \text { Ya } & 26 & 47,3 \\ \text { Tidak } & 29 & 52,7\end{array}$

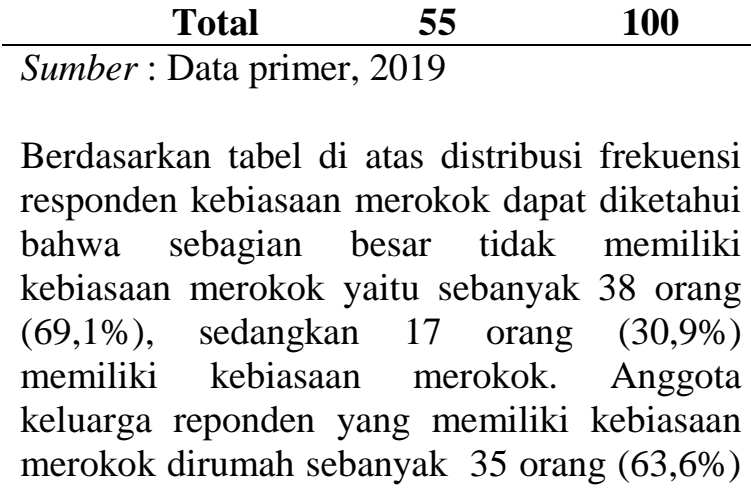


sedangkan 20 orang $(36,4 \%)$ anggota keluarganya tidak merokok dan responden sebagian besar tidak terpapar asap rokok sebanyak 29 orang $(52,7 \%)$ sedangkan 26 orang $(47,3 \%)$ sering terpapar asap rokok di tempat kerja.
Tabel 9

Distribusi Frekuensi Responden

Berdasarkan Tingkat Aktivitas Fisik

\begin{tabular}{|c|c|c|c|}
\hline No & Variabel & Frekuensi & $\begin{array}{c}\text { Presentase } \\
\%\end{array}$ \\
\hline 1 & Kebiasaan & & \\
\hline
\end{tabular}

Ya

18

32,7

Tidak

37

67,3

Berdasarkan Kebiasaan Makan

\begin{tabular}{cccc}
\hline \multicolumn{3}{c}{ Berdasarkan Kebiasaan Makan } \\
No & Variabel & Frekuensi & $\begin{array}{c}\text { Presentase } \\
\%\end{array}$ \\
\hline 1 & Makan asin : & & \\
& Ya & 34 & 61,8 \\
& Tidak & 21 & 38,2 \\
& & & 3
\end{tabular}

2 Makan lemak:

$\begin{array}{cc}\text { Ya } & 36 \\ \text { Tidak } & 19\end{array}$

65,5

Waktu

olahraga

(menit):

Ya

39

70,9

Tidak

Waktu

olahraga

(seminggu):

934,5

3 Makan instan:

Ya

31

Tidak

24
34,5

$$
\text { Ya }
$$

38

17

aktivitas

56,4

43,6

100

berat:

Ya
4 Tingkat
Total

Tidak

Tingkat

aktivitas

ringan:

Ya

Tidak

6 Kebiasaan

asin, dan responden yang memiliki kebiasaan mengkonsumsi makanan berlemak lebih dari 3 kali dalam seminggu sebanyak 36 orang $(65,5 \%)$ dan 19 orang $(34,5 \%)$ tidak, sedangkan responden yang memiliki kebiasaan makan makanan instan sebanyak 1-2 kali dalam seminggu atau lebih yaitu 31 orang $(56,4 \%)$ dan yang tidak sebanyak 24 orang $(43,6 \%)$.

Berdasarkan tabel 4.5 distribusi frekuensi responden yang memiliki kebiasaan makan makanan asin yaitu sebanyak 34 orang $(61,8 \%)$ sedangkan 21 orang $(38,2)$ tidak

\section{$(43,6 \%)$}

(n) duduk:

Ya

Tidak

\begin{tabular}{|c|c|c|c|}
\hline \multirow{5}{*}{7} & $\mathrm{Ya}$ & 29 & 52,7 \\
\hline & Tidak & 26 & 47,3 \\
\hline & $\begin{array}{c}\text { Kebiasaan } \\
\text { bersepeda } \\
\text { motor: }\end{array}$ & & \\
\hline & Ya & 25 & 45,5 \\
\hline & Tidak & 30 & 54,5 \\
\hline & Total & 55 & 100 \\
\hline
\end{tabular}

Sumber: Data Primer, 2019

Berdasarkan tabel di atas distribusi frekuensi responden sesuai tingkat aktivitas fisik menunjukkan bahwa sebagian responden rutin melakukan olahraga sebanyak 37 orang $(67,3 \%)$ sedangkan 18 orang $(32,7 \%)$ tidak rutin melakukan olahraga, dan sebagian besar responden berjumlah 39 orang $(70,9 \%)$ melakukan olahraga menggunakan waktu kurang dari 30 menit sedangkan 16 orang 
melakukan olahraga menggunakan waktu lebih dari 30 menit. 38 orang $(69,1)$ melakukan olahraga kurang dari 3 kali perminggu, dan 17 orang lainnya melakukan olahraga lebih dari 3 kali perminggu. Responden berdasarkan tingkat aktivitas berat sebanyak 33 orang $(60,0 \%)$ sedangkan $22(40,0 \%)$ orang lainnya tidak melakukan aktivitas berat. 41 orang $(74,5 \%)$ melakukan aktivitas ringan dan 14 responden lain tidak melakukan aktifitas ringan. Responden yang memiliki kebiasaan duduk sebanyak 29 orang $(52,7 \%)$ dan yang tidak memiliki kebisaaan duduk 26 orang $(47,3 \%)$ dan responden yang memiliki kebiasaan berjalan menggunakan sepeda motor sebanyak 25 orang $(45,5 \%)$ sedangkan 30 orang $(54,5 \%)$ lainnya tidak.

\section{Tabel 10}

Distribusi Frekuensi Responden Berdasarkan Faktor Resiko Hipertensi : Stress

\begin{tabular}{ccc}
\hline Variabel & Total & Presentase \\
\hline Tidak stress & 22 & 40 \\
Stress ringan & 19 & 34,5 \\
Stress sedang & 8 & 14,5 \\
Stress berat & 6 & 10,9 \\
Stress berat sekali & 0 & 0 \\
\hline Total & $\mathbf{5 5}$ & $\mathbf{1 0 0}$ \\
\hline
\end{tabular}

Sumber: Data Primer, 2019

Berdasarkan tabel diatas dapat diketahui bahwa dari 55 responden yang tidak mengalami stress sebanyak 22 orang (40\%), stresss ringan 19 orang $(34,5 \%)$, yang mengalami stress sedang sebanyak 8 orang $(14,5 \%)$, stress berat 6 orang $(10,9 \%)$ dan tidak ada yang mengalami stress berat.

\section{PEMBAHASAN}

\section{a. Responden Berdasarkan Kebiasaan Merokok}

Berdasarkan tabel di atas distribusi frekuensi responden kebiasaan merokok dapat diketahui bahwa sebagian besar tidak memiliki kebiasaan merokok yaitu sebanyak 38 orang $(69,1 \%)$, sedangkan 17 orang $(30,9 \%)$ memiliki kebiasaan merokok. Anggota keluarga reponden yang memiliki kebiasaan merokok dirumah sebanyak 35 orang $(63,6 \%)$ sedangkan 20 orang $(36,4 \%)$ anggota keluarganya tidak merokok dan responden sebagian besar tidak terpapar asap rokok sebanyak 29 orang $(52,7 \%)$ sedangkan 26 orang $(47,3 \%)$ sering terpapar asap rokok di tempat kerja. Hal ini sejalan dengan penelitian yang dilakukan oleh Pusparani (2016), dimana responden terbanyak ialah perokok aktif.

Risiko merokok terbesar tergantung pada jumlah rokok yangdihisap perhari. Seseorang lebih dari satu bungkus rokok sehari menjadi 2 kalilebih rentan hipertensi dari pada mereka yang tidak merokok. Zat-zatkimia beracun, seperti nikotin dan karbon monoksida yang diisap melalui rokok, yang masuk kedalam aliran darah dapat merusak lapisan endotelpembuluh darah arteri dan mengakibatkan proses aterosklerosis dan hipertensi (Marliani, 2007). Hasil penelitian ini juga sejalan dengan hasil penelitian Hanafi, dimana responden terbanyak ialah perokok pasif.

Menurut pendapat peneliti seseorang yang merokok lebih dari satu bungkus rokok sehari menjadi 2 kali lebih rentan hipertensi daripada mereka yang tidak merokok dan yang sering terpapar asap rokok akan mudah mengalami hipertensi, karena zat-zat kimia yang terkandung didalam rokok dapat menyebabkan kerusakan organ dalam tubuh yang mampu menyebabkan hipertensi.

\section{b. Tingkat Aktivitas Fisik}

Berdasarkan hasil penelitian responden sesuai tingkat aktivitas fisik menunjukkan bahwa sebagian responden rutin melakukan olahraga sebanyak 37 orang $(67,3 \%)$ sedangkan 18 orang $(32,7 \%)$ tidak rutin melakukan olahraga, dan sebagian besar responden berjumlah 39 orang $(70,9 \%)$ melakukan olahraga menggunakan waktu kurang dari 30 menit sedangkan 16 orang melakukan olahraga menggunakan waktu lebih dari 30 menit. 38 orang $(69,1)$ melakukan olahraga kurang dari 3 kali perminggu, dan 17 orang lainnya melakukan olahraga lebih dari 3 kali perminggu. Responden berdasarkan tingkat aktivitas berat sebanyak 33 orang $(60,0 \%)$ sedangkan $22(40,0 \%)$ orang lainnya tidak melakukan aktivitas berat. 41 orang $(74,5 \%)$ melakukan aktivitas ringan dan 14 responden lain tidak melakukan aktifitas ringan. Responden yang memiliki kebiasaan duduk sebanyak 29 orang $(52,7 \%)$ dan yang tidak memiliki kebisaaan 
duduk 26 orang $(47,3 \%)$ dan responden yang memiliki kebiasaan berjalan menggunakan sepeda motor sebanyak 25orang $(45,5 \%)$ sedangkan 30 orang $(54,5 \%)$ lainnya tidak.Hal ini sejalan dengan hasil penelitian yang dilakukan oleh Pusparani (2016) yang menyatakan bahwa ada hubungan antara aktifitas fisik dengan kejadian hipertensi.

Menurut Depkes (2006), seseorang yang dikatakan olahragaapabila melakukan olahraga selama >30 menit dan 3-4 kali/minggu. Indeksaktivitas fisik responden pada waktu melakukan pekerjaan, olahraga danpada waktu luang.

Menurut pendapat peneliti jika rutin melakukan olahraga dan aktivitas fisik dapat mengurangi resiko terjadinya hipertensi,melatih otot jantung karena jika kita sering melakukan aktivitas dan olahraga dapat menurunkan faktor resiko hipertensi.

\section{c. Kebiasaan Makan}

Berdasarkan hasil penelitian frekuensi responden yang memiliki kebiasaan makan makanan asin yaitu sebanyak 34 orang $(61,8 \%)$ sedangkan 21 orang $(38,2)$ tidak memiliki kebiasaan makan asin, dan responden yang memiliki kebiasaan mengkonsumsi makanan berlemak lebih dari 3 kali dalam seminggu sebanyak 36 orang $(65,5 \%)$ dan 19 orang $(34,5 \%)$ tidak, sedangkan responden yang memiliki kebiasaan makan makanan instan sebanyak 1-2 kali dalam seminggu atau lebih yaitu 31 orang $(56,4 \%)$ dan yang tidak sebanyak 24 orang $(43,6 \%)$.

Hasil penelitian ini sesuai dengan penelitian yang dilakukan oleh Hanafi (2016) yang menilai kebiasaan mengkonsumsi makanan asin, makanan berlemak dn makanan instan. Hasil penelitiannya itu menunjukan bahwa sebagian besar responden memiliki kebiasaan makan yang tidak baik. Sebagaimana penelitian yang ditemukan oleh (Berek, 2018) hasil penelitian menunjukan penurunan tekanan darah sistolik sebesar 28,59 $\mathrm{mmHg}$ dan tekanan darah diastolik $16,92 \mathrm{mmHg}$ dengan mengatur konsumsi garam 2,4 gram/hari.

Menurut peneiliti kebiasaan mengkonsumsi makan makanan asin, makanan berlemak dan makanan instan sangat berpengaruh pada penyakit hipertensi, karena makanan asin dan makanan berlemak merupakan salah satu faktor yang dapat menyebabkan hipertensi.

\section{d. Faktor Resiko Hipertensi: Stress}

Berdasarkan hasil penelitiankeadaan stress dapat diketahui bahwa sebanyak 22 orang (40\%), stresss ringan 19 orang $(34,5 \%)$, yang mengalami stress sedang sebanyak 8 orang $(14,5 \%)$, stress berat 6 orang $(10,9 \%)$ dan tidak ada yang mengalami stress berat.

Hormon epinerfin dan kortisol yang dilepaskan saat stres menyebabakan peningkatan tekanan darah dengan menyempitkan pembuluh darah dan meningkatkan denyut jantung. Besarnya peningkatan tekanan darah tergantung pada beratnya stress, koping yang adekuat dapat berpengaruh baik terhadap penurunan tekanan darah (Sheps, 2005 dalam Pusparani, 2016).Hal ini sejalan dengan penelitian yang dilakukan oleh Pusparani, yang menyatakan bahwa stress mempunyai hubungan bermakna dengan kejadian hipertensi.

Menurut pendapat peneliti stress sangat berpengaruh terhadap hipertensi, karena pada saat kita mengalami stress akan menyebabkan peningkatan tekanan darah dan denyut jantung.

\section{KESIMPULAN}

Berdasarkan hasil penelitian dengan judul Gambaran Gaya Hidup Penderita Hipertensi di Puskesmas Atambua Selatan, peneliti mengambil kesimpulan.

Karakteristik responden penelitian yaitu ratarata usia responden 54,18 tahun, rata-rata jenis kelamin responden terbanyak adalah laki-laki yaitu 50,9, tingkat pendidikan responden paling banyak SLTP sebanyak 38,2\%, pekerjaan responden terbanyak yaitu tidak bekerja sebanyak 49,1\% dan 96,4\% tidak memiliki penyakit komplikasi.

Sebagian besar responden tidak memiliki kebiasaan merokok yaitu sebanyak 38 orang $(69,1 \%)$, dan paparan asap rokok dari anggota keluarga responden sangat besar yaitu 35 orang $(63,6 \%)$ sedangkan paparan asap rokok di tempat kerja/kantor rendah yaitu 26 orang $(47,3 \%)$.

Sebagian besar responden memiliki kebiasaan makan yang tidak baik yaitu makan makanan asin yaitu sebanyak 34 orang $(61,8 \%)$, 
kebiasaan mengkonsumsi makanan berlemak lebih dari 3 kali dalam seminggu sebanyak 36 orang $(65,5 \%)$, sedangkan responden yang memiliki kebiasaan makan makanan instan sebanyak 1-2 kali dalam seminggu atau lebih yaitu 31 orang $(56,4 \%)$.

Lebih dari separuh responden memiliki tingkat aktivitas fisik yang tidak baik yaitu sebagian responden rutin melakukan olahraga sebanyak 37 orang $(67,3 \%)$, dan sebagian besar responden berjumlah 39 orang $(70,9 \%)$ melakukan olahraga menggunakan waktu kurang dari 30 menit, 38 orang $(69,1)$ melakukan olahraga kurang dari 3 kali perminggu. Responden berdasarkan tingkat aktivitas berat sebanyak 33 orang $(60,0 \%), 41$ orang $(74,5 \%)$ melakukan aktivitas, responden yang memiliki kebiasaan duduk sebanyak 29 orang $(52,7 \%)$ dan responden yang memiliki kebiasaan berjalan menggunakan sepeda motor sebanyak 25orang (45,5\%).

Sebagian besar responden dalam keaadaan baik dan tidak mengalami stress.

\section{SARAN}

\section{Bagi Peneliti}

Penelitian ini diharapkan dapat menambah wawasan baru bagi penelititentang Gambaran Gaya Hidup Penderita Hipertensi.

\section{Bagi Masyarakat}

Diharapkan dapat memberikan masukam bagi masyarakat untuk memperbaiki gaya hidup yang lebih sehat untuk mengontrol tekanan darah.

3. 3. Bagi Institusi Keperawatan

Penelitian ini diharapkan dapat menambah dan meningkatkan pengetahuan pembaca tentang Gambaran Gaya Hidup Penderita Hipertensi.

\section{DAFTAR PUSTAKA}

Alfyan, Susanto, Khadizah. 2017. "Kualitas Hidup Pasien Dengan Hipertensi" . Akademi Farmasi ISFI Banjarmasin.

Anugrahini, C. 2016, "Panduan Penyusunan Karya Tulis Ilmiah" Studi Kasus DIII Keperawatan.

Artiyaningrum, 2015. "Faktor-faktor Yang Berhubungan Dengan Kejadian Hipertensi”. Universitas Negeri Malang.
Berek, P. A. L. (2018). PENGARUH SLOW

DEEP BREATHING DAN

PENGATURAN NATRIUM

TERHADAP PENURUNAN

TEKANAN DARAH PASIEN

HIPERTENSI PRIMER. Prosiding

Sintesa LP2M UNDHIRA BALI, 2

November(November), 499-508.

Retrieved from

https://jurnal.undhirabali.ac.id/index.php/

sintesa/article/view/521

Berek, P. A. L., Nurachmah, E., \& Gayatri, D. (2015). Effectiveness Of Slow Deep

Breathing On Decreasing Blood Pressure

In Primary Hypertension : A

Randomized Contrrolled Trial Of

Patients In Atambua, East Nusa

Tenggara. International Journal of

Science and Technology, 1(2), 1-14.

Retrieved from

http://grdspublishing.org/MATTER/matt er.html

Fatmawati, Junald, Ibrahim. 2017. "Hipertensi pada Usia Dewasa". Fakultas Kesehatan Mayarakat.

Handayani, Rusli, Ibrahim. 2015. "Analisis Karakteristik dan Kejadian Drug Related Problems pada pasien Hipertensi”. Universitas Mulawarman, Samarinda Kalimantan Timur.

Ibrahim, 2017. "Hubungan Life Style Dengan Kejadian Hipertensi". Fakultas Kesehatan Masyarakat universitas Hau Ole.

Kamaludin, 2010. "Pengalaman Pasien Hipertensi yang Menjalani Terapi Alternatif komplementer". Fakultas ilmu Keperawatan Program Magister Keperawatan Kekhususan Keperawatan Medikal Bedah Depok.

Martins, 2018 "Asuhan Keperawatan Hipertensi". Universita Timor.

Nisa, 2018. "Gambaran Gaya Hidup Penderita Hipertensi di Puskesmas Bonang 1 Demak" Universitas Muhamadiyah Semarang. 
Nursalam. 2008. "Konsep dan Penerapan Metodologi Penelitian Ilmu Keperawatan : Pedoman Skripsi, Tesis, Olah Instrumen Penelitian Keperawatan”. Jakarta. Salemba Medika.

Pusparani, 2016 "Gambaran Gaya Hidup Penderita Hipertensi". Universitas Islam Negeri Syarif Hidayatullah.

Rahma, 2017 "Gambaran Gaya Hidup Penderita Hipertensi" Departemen Ilmu Keperawatan Universitas Diponegoro.

Sinaga, 2012. "Gambaran Tingkat Pengetahuan Penderita Hipertensi". Fakultas Keperawatan Depok.

Sinubu, Rondonuwu, Onibala. 2015. "Hubungan Beban Kerja Dengan Kejadian Hipertensi" Universitas Sam Ratulangi Manado. 
